\title{
Rancang Bangun Infrastruktur Wireless \\ Dengan Pendekatan Metode Line Of Sight
}

\author{
Lilik Suhery \\ Teknik Komputer, Sekolah Tinggi Teknologi Payakumbuh \\ email: liliksuheri@gmail.com
}

\begin{abstract}
The design of wireless infrastructure with the approach line of sight can give an idea of how the application of technology in an area. Placement of proper installation of wireless transmitter is needed to optimize signal strength, using the approach of line of sight. Things that affect the design of wireless infrastructure is the value of the amount of signal strength that can be received by users of wireless networks. The parameters used in to make the measurement is to check the power of the transmitter antenna to a receiver that is measured by using ViStumbler who works at a frequency of $2.4 \mathrm{GHz}$. In this measurement is also used propagation Line Of Sight. The results showed that the fewer obstructions the wireless signal in the determination of Line Of Sight then the better quality of wireless services
\end{abstract}

Keywords: Wireless, Line Of Sight, ViStumbler, Fresnel Zone

Abstrak: Perancangan infrastruktur wireless dengan pendekatan line of sight dapat memberikan gambaran bagaimana penerapan teknologi dalam suatu area. Penempatan pemasangan pemancar wireless yang tepat sangat diperlukan untuk mengoptimalkan kekuatan sinyal, dengan menggunakan metode pendekatan line of sight. Hal yang mempengaruhi perancangan infrastruktur wireless adalah nilai besaran kekuatan sinyal yang dapat diterima oleh pengguna jaringan wireless. Parameter yang digunakan dalam untuk melakukan pengukuran adalah dengan mengecek kekuatan daya pemancar antenna terhadap penerima yang diukur dengan menggunakan ViStumbler yang bekerja pada frekuensi 2,4 GHz. Pada pengukuran ini juga digunakan propagasi Line Of Sight. Hasil penelitian menunjukkan bahwa semakin sedikit penghalang sinyal wireless dalam penentuan Line Of Sight maka kualitas layanan wireless semakin bagus.

Kata kunci: Wireless, Line Of Sight, ViStumbler, Fresnel Zone

\section{PENDAHULUAN}

Kebutuhan akan sistem untuk komunikasi jarak jauh semakin meningkat sejalan dengan era globalisasi dimana perpindahan dan pergerakan manusia semakin berkembang dengan cepat dan meluas. Perkembangan tersebut memacu untuk menghadirkan teknologi sampai ke semua wilayah termasuk daerah terpencil di pedesaan yaitu dengan menggunakan teknologi WLAN (Manurung \& Mubarakah, 2014)

Dalam mengakses layanan internet dengan menggunakan wireless, sering kali ditemui adanya wilayah wilayah yang sinyal akses nya kurang bagus atau bahkan terdapat sinyal sinyal wireless yang bertumpukan. Hal ini tentu dapat menimbulkan gangguan dalam menggunakan layanan system Wifi. Sementara itu di lain area tidak terdapat koneksi sama sekali (Blank spot area), oleh karena itu dibutuhkan perencanaan dan perancangan yang baik dalam pemasangan infrastruktur wireless pada suatu wilayah agar dapat meningkatkan kualitas akses terhadap layanan wireless itu sendiri Transmisi radio dipengaruhi oleh beberapa faktor, salah satunya adalah propagasi antara Transmitter dan Receiver (kondisi LOS atau NLOS) (Harinitha, 2012).

Secara definisi, Line of Sight (LOS) merupakan Visual Line of Sight yang menjelaskan kemampuan rata-rata mata manusia untuk melihat benda yang cukup jauh. Sedangkan kondisi Non Line of Sight atau Near Line of Sight (NLOS) digunakan untuk mendeskripsikan transmisi radio melalui jalur yang diblok/ terhalangi secara parsial, biasanya berupa objek fisik dalam zona Fresnel. Penghalang yang dapat menyebabkan kondisi NLOS adalah bangunan, pepohonan, bukit, gunung dan pegunungan. Pada beberapa kasus, tegangan tinggi pada sambungan listrik dapat juga menjadi penghalang. Beberapa dari penghalang tersebut menyebabkan gelombang radio dipantulkan, diserap, atau menimbulkan 
distorsi sehingga dapat membatasi penggunaan transmisi radio (Haryadi \& Satria, n.d.)

Menurut (Sari, Tribudi, \& Siswandi, 2010) diperlukan system penataan letak sistem Wi-Fi agar bisa optimal sehingga semua pengguna di area tersebut bisa menikmati layanan internet tanpa ada gangguan dan tidak kehilangan koneksi

Oleh karena itu maka dibutuhkan penempatan pemancar wireless yang benar agar hasil yang didapatkan sesuai dengan kebutuhan, serta meratanya sebaran sinyal wireless ketertarikan peneliti untuk melakukan penelitian ini disebabkan karena peneliti bermaksud akan melakukan optimisasi terhadap access point pada jaringan Wi-Fi. Hasil penelitian (Puspitasari \& Pulungan, n.d.) memperlihatkan cara untuk menentukan coverage area maksimum dengan metode Monte Carlo berdasarkan fungsi jarak dari hasil pengukuran di lapangan. Dari penelitian tersebut dapat disimpulkan bahwa berdasarkan hasil pengukuran dapat diketahui bahwa level daya terima berbanding terbalik dengan jarak antara pemancar (Tx) dan penerima $(\mathrm{Rx})$, semakin jauh jarak antara pemancar $(\mathrm{Tx})$ dan penerima $(\mathrm{Rx})$ maka level daya terima semakin kecil.

\section{METODE PENELITIAN}

Penelitian dilakukan di lingkungan kampus Sekolah Tinggi Teknologi Payakumbuh. Bahan yang dibutuhkan adalah perangkat lunak pengukur propagasi sinyal wireless serta kabel UTP sebagai penghubung perangkat wireless. Peralatan yang digunakan ada sebuah wireless Access point TL-WA5210G sebagai pemancar sinyal dan sebuah laptop yang telah terpasang wireless card untuk menguji kuat sinyal propagasi.

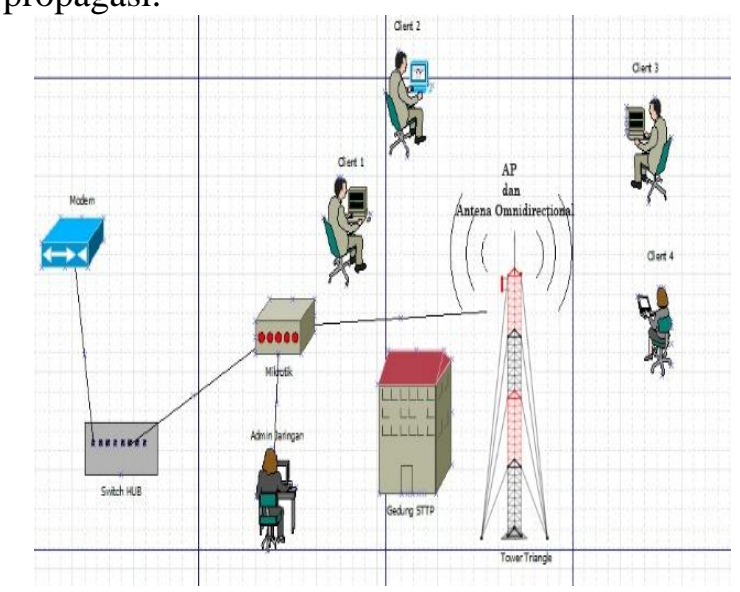

Gambar 1. Topologi Jaringan Wireless

Topologi jaringan ini digunakan sebagai rancangan awal pembuatan jaringan wireless, dimana nantinya akan ditentukan beberapa titik pengujian kuat sinyal berdasarkan Line of Sight pada pemancar wireless sebagaimana tertera pada tabel.1

Tabel.1 Lokasi kuat sinyal

\begin{tabular}{clc}
\hline No & \multicolumn{1}{c}{ Lokasi } & Jarak \\
\hline 1 & Pos Satpam & $20 \mathrm{~m}$ \\
2 & Kantin Depan & $22 \mathrm{~m}$ \\
3 & Parkiran & $18 \mathrm{~m}$ \\
4 & Kantin Belakang & $15 \mathrm{~m}$ \\
5 & Bangunan Baru & $25 \mathrm{~m}$ \\
6 & Belakang Pustaka & $15 \mathrm{~m}$ \\
7 & Labor D & $4 \mathrm{~m}$ \\
8 & Prodi dan Akademik & $10 \mathrm{~m}$ \\
\hline
\end{tabular}

\section{HASIL DAN PEMBAHASAN}

Data hasil eksperimen kuat sinyal pada beberapa titik yang telah ditentukan pada tabel 1 , maka di dapatkan hasil ditunjukkan pada tabel 2.

Tabel 2. Hasil Pengukuran Kuat Sinyal

\begin{tabular}{clcc}
\hline No & \multicolumn{1}{c}{ Lokasi } & Jarak & Sinyal \\
\hline 1 & Pos Satpam & $20 \mathrm{~m}$ & $13 \%$ \\
2 & Kantin Depan & $22 \mathrm{~m}$ & $0 \%$ \\
3 & Parkiran & $18 \mathrm{~m}$ & $32 \%$ \\
4 & Kantin Belakang & $15 \mathrm{~m}$ & $38 \%$ \\
5 & Bangunan Baru & $25 \mathrm{~m}$ & $50 \%$ \\
6 & Belakang Pustaka & $15 \mathrm{~m}$ & $71 \%$ \\
7 & Labor D & $4 \mathrm{~m}$ & $12 \%$ \\
8 & Prodi dan & $10 \mathrm{~m}$ & $44 \%$ \\
& Akademik & & \\
\hline
\end{tabular}

Kuat sinyal yang paling rendah adalah pada lokasi 2 yaitu pada posisi kantin depan, dimana kuat sinyalnya adalah sebesar $0 \%$.

Pada pengukuran di kantin depan, sinyal tidak sampai dikarenakan penghalang lebih tinggi dari pada access point, sehingga LOS (Line Of Sight) antara pemancar dan penerima tidak terlihat, ditambah lagi antara pemancar dan penerima banyak terdapat penghalang (bangunan) yang mengakibatkan wilayah fresnel zone tidak sampai pada posisi penerima. Dimana gambaran dari analisa fresnel zone dan hambatannya adalah sebagai berikut

$$
r=17,32 \times \sqrt{\left(\frac{0,022}{4 \times 2,4}\right)} \quad r=0,82 \mathrm{~m}
$$

Pada pengukuran ini $100 \%$ fresnel zone di block oleh penghalang, yang berarti 100\%x 0,82 
$=0,82 \mathrm{~m}$, seluruh wilayah fresnel zone terhalang, sehingga hubungan pemancar dan penerima terputus.

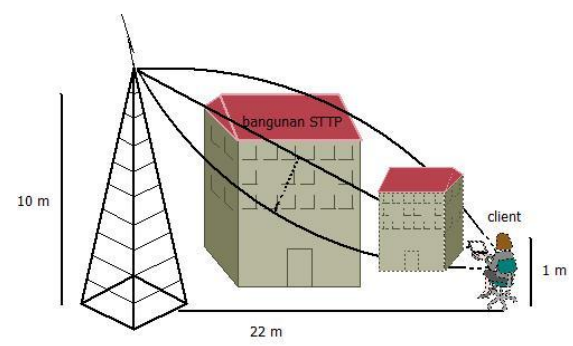

Gambar 4.13 Analisa pada kantin depan

Kuat sinyal yang paling tinggi adalah pada lokasi 6 yaitu bangunan pustaka, dimana kuat sinyalnya adalah sebesar $71 \%$. Pada pengukuran di bagian belakang pustaka, sinyal yang didapat $71 \%$, LOS (Line Of Sight) antara pemancar dan penerima tidak terhalang, bukan berarti sinyal full sampai ke penerima, melainkan sinyal semakin kecil sampai ke penerima.

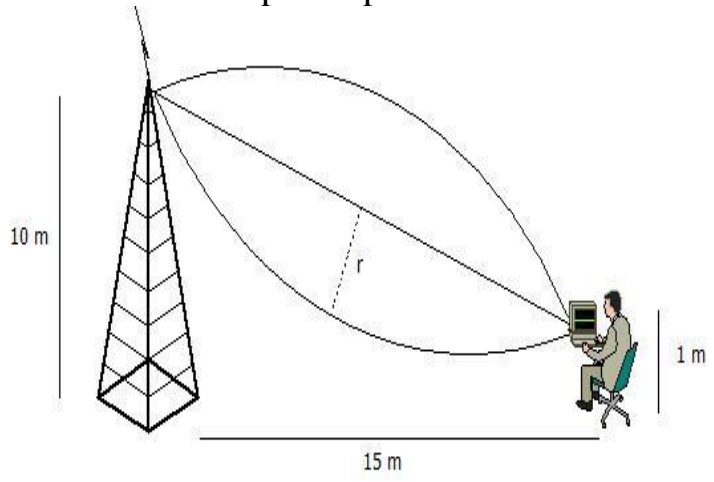

Gambar 4.19 Analisa pada bagian bangunan pustaka

$$
r=17,32 \times \sqrt{\left(\frac{0.015}{4 \times 2.4}\right)}
$$

$\mathrm{r}=0,68 \mathrm{~m}$

Area $100 \%$ wilayah Fresnel zone terbebas dari penghalang, dimana perhitungannya adalah $100 \% \times 0,68=0,68 \mathrm{~m}$, dengan asumsi dari pemancar ke titik penerima tidak ada penghalang

\section{SIMPULAN}

Berdasarkan penelitian yang telah dilakukan, maka dapat diambil kesimpulan bahwa perancangan jaringan wireless menggunakan metode pendekatan Line Of Sight (LOS) dapat menjadi salah satu pertimbangan dalam merancang sebuah jaringan wireless.
Jaringan yang memiliki Line of sight dan penghalang yang tinggi, maka akan memiliki cakupan kuat sinyal yang rendah. Sedangkan jaringan yang memiliki line of sight dan penghalang yang rendah, maka akan memiliki cakupan kuat sinyal yang lumayan tinggi.

\section{UCAPAN TERIMAKASIH}

Ucapan terima kasih atas bantuan dari rekan dosen dan staf laboratorium STT Payakumbuh serta semua pihak-pihak yang telah membantu terlaksananya penelitian ini.

\section{DAFTAR PUSTAKA}

Harinitha, D. (2012). NLOS Wireless $300-400$

MHz Pada Daerah Rural, 5(1), 107-121.

Haryadi, S., \& Satria, H. (n.d.). Outdoor Line of

Sight Wireless Optical Communication

System.

Kom, Hariyadi M. "Pengelolaan Jalur Data Menggunakan "XXX" Bandwith

Management Pada ISP WAN." Menara Ilmu 10.60-65 (2016).

Manurung, F. A., \& Mubarakah, N. (2014). Analisis Link Budget Untuk Koneksi Radio Wireless Local Area Network. Singuda Ensikom, 7(2), 82-87.

Puspitasari, N. F., \& Pulungan, R. (n.d.).

Optimisasi Penempatan Posisi Access Point Pada Jaringan Wi-Fi Menggunakan Metode Simulated Annealing.

Sari, P. I., Tribudi, S., \& Siswandi, A. N. (2010). Optimasi Penataan Sistem Wi-Fi di PENSITS dengan Menggunakan Metode Monte Carlo, 1-7. 